\title{
Prevalence of Metabolic Syndrome in Local Population of Patan.
}

Babu Raja Maharjan¹, Shital Bhandary², Ira Shrestha ${ }^{3}$, Laxmi Sunuwar ${ }^{3}$, Sanjit Shrestha4.

${ }^{1}$ Department of Biochemistry, ${ }^{2}$ Department of Community Health Sciences, ${ }^{3}$ Department of Physiology, Patan Academy of Health Sciences, Department of Pathology, Kathmandu Model Hospital ${ }^{4}$.

\begin{abstract}
Introduction: The metabolic syndrome (MS) is a cluster of complex interrelated risk factors for diabetes and cardiovascular disease which includes central obesity, glucose intolerance, hypertension, high triglyceride and low HDL-C. The prevalence of MS in Asian Indian is 49.2\%. There is evidence of increasing prevalence of MS in the world. Therefore, we intended to find the prevalence of the metabolic syndrome in the local population of Patan, a major urban center in Nepal.

Methods: It was a cross-sectional study which was carried out in one of the urban clusters (or wards) of the Lalitpur SubMetropolitan (or Patan) City. Measurements of waist circumference, height, weight; blood parameters like lipid profile, fasting blood sugar (FBS) were done. Measurement of blood pressure was done. The prevalence of MS was obtained by using three different criteria Joint Interim Statement 2009 criteria, International diabetes federation (IDF) 2005 criteria and National cholesterol education program adult treatment Panel (NCEP ATP) III 2001 criteria.

Results: There were 205 participants among which 34.6\% were male and $65.4 \%$ were female. The prevalence of MS as per the Joint Interim Statement 2009, IDF 2005 and NCEP ATP III 2001 criteria was $61.7 \%, 52.7 \%$ and $43.4 \%$ respectively. There was significantly high total cholesterol (TC), triglyceride (TAG), FBS, systolic blood pressure (SBP) and diastolic blood pressure (DBP) and significantly low HDL-C in the individuals with MS compared to the normal individuals. The logistic regression revealed the increasing prevalence of MS with increasing age, BMI and positive family history of diabetes.
\end{abstract}

Conclusions: There is high prevalence of MS in the study population. Age, BMI and family history of diabetes are found to be the main predictors for metabolic syndrome.

Keywords: lipid profile, metabolic syndrome, prevalence, screening.

\section{INTRODUCTION}

The metabolic syndrome (MS) is a cluster of complex interrelated risk factors for diabetes and cardiovascular disease which includes central obesity, glucose intolerance, hypertension, high triglyceride and low high density lipoprotein ${ }^{1}$. People with MS are twice as likely to die from, and three times as likely to have a heart attack or stroke compared with people without the MS. People with MS have a five-fold greater risk of developing type 2 diabetes ${ }^{2}$. In addition MS is associated with all cause of mortality ${ }^{3}$.Unfortunately, the quarter of world's population have metabolic syndrome ${ }^{2}$.Evidences suggest that it is growing which has made MS as the major public health issues.

\footnotetext{
Correspondence:

Babu Raja Maharjan

Department of Biochemistry, Patan Academy of Health Sciences. Kathmandu, Nepal

Email: baburajamaharjan@pahs.edu.np

Phone: +977-9841255663
} 
The prevalence of MS in Asian Indian is $49.2 \%{ }^{4}$ and it is also increasing in developing countries ${ }^{5-7}$. Rapid nutritional and lifestyle transition in urbanized areas in various countries in South Asia are identified as a prime reason for increasing prevalence of the metabolic syndrome ${ }^{8-9}$. This in turn has been associated with a growing burden of type 2 diabetes and cardiovascular disease in this region ${ }^{10-11}$. Lifestyle modification and exercise have been proven effective for the prevention of these non communicable diseases. We, therefore, have intended to find the prevalence of the metabolic syndrome in the local population of Patan, a major urban center in Nepal so that preventive measures can be taken.

\section{METHODS}

It was a cross-sectional study carried out in one of the urban clusters (or wards) of the Lalitpur Sub-Metropolitan (or Patan) City. The study population was obtained from a three day screening camp organized in the month of November 2009.

A pre-tested semi-structured questionnaire was administered.Palpatatory method of blood pressure measurement was used first which was followed by auscultatory method with a properly calibrated and validated instrument. Individuals were allowed to sit quietly for at least 5 minutes in a chair. Systolic Blood Pressure (SBP) was recorded at the point at which the first of 2 or more sounds is heard and Diastolic Blood Pressure (DBP) at the point before the disappearance of sounds. ${ }^{12}$

Height was measured in centimeter and weight in kilogram and body mass index (BMI) was calculated. Waist circumference (WC) was measured using soft tape in centimeter on the standing subject between the lower rib and iliac crest. Hip circumference was measured over the widest part of the gluteal region with two legs joined.

Fasting blood was collected after an overnight fast for biochemical analysis of blood sugar, total cholesterol (TC), triglycerides (TAG), HDL-C, LDL-C and VLDL-C. Fasting blood sugar (FBS) was estimated by glucose oxidase peroxidase method $^{13}$, total cholesterol was measured by cholesterol oxidase-peroxidse method ${ }^{14}$ and triglyceride were measured by glycerol phosphate oxidase method ${ }^{15}$ and $\mathrm{HDL}-\mathrm{C}$ was measured by the direct immunoseparation method $^{16}$. The reagents were from Human, Germany. LDL-Cwas calculated by Friedwald Formula. ${ }^{17}$ Fully auto analyzer Humstar 600 (Germany) was used for the biochemical analysis of the sample.

The prevalence of MS was obtained by using three different criteria as follows:

\section{Joint Interim Statement 2009 criteria $^{18}$.}

If any three of the following five factors were positive: $W C \geq 90 \mathrm{~cm}$ (male) and $\geq 80 \mathrm{~cm}$ (female), FBS $\geq 100 \mathrm{mg} / \mathrm{dl}$ or on medication for diabetes, TAG $\geq 150 \mathrm{mg} / \mathrm{dl}, \mathrm{HDL}<40 \mathrm{mg} /$ $\mathrm{dl}$ (male) and $<50 \mathrm{mg} / \mathrm{dl}$ (female), SBP $\geq 130 \mathrm{~mm}$ of $\mathrm{Hg}$ and/ or $\mathrm{DBP} \geq 85 \mathrm{~mm}$ of $\mathrm{Hg}$.

\section{IDF 2005 criteria $^{19}$.}

If $W C \geq 90 \mathrm{~cm}$ (male) and $\geq 80 \mathrm{~cm}$ (female) and any two of the following four factors were positive: FBS $\geq 100 \mathrm{mg} /$ $\mathrm{dl}$ or preexisting diabetes, TAG $\geq 150 \mathrm{mg} / \mathrm{dl}, \mathrm{HDL}<40 \mathrm{mg} /$ $\mathrm{dl}$ (male) and $<50 \mathrm{mg} / \mathrm{dl}$ (female), SBP $\geq 130 \mathrm{~mm}$ of $\mathrm{Hg}$ and/ or $\mathrm{DBP} \geq 85 \mathrm{~mm}$ of $\mathrm{Hg}$.

\section{NCEP ATP III 2001 criteria $^{20}$.}

If any three of the following five factors were positive: waist circumference $\geq 102 \mathrm{~cm}$ (male) and $\geq 88 \mathrm{~cm}$ (female), FBS $\geq 110 \mathrm{mg} / \mathrm{dl}$ or on medication for diabetes, TAG $\geq 150$ $\mathrm{mg} / \mathrm{dl}, \mathrm{HDL}<40 \mathrm{mg} / \mathrm{dl}$ (male) and $<50 \mathrm{mg} / \mathrm{dl}$ (female), $\mathrm{SBP} \geq 130 \mathrm{~mm}$ of $\mathrm{Hg}$ and/or DBP $\geq 85 \mathrm{~mm}$ of $\mathrm{Hg}$.

Data was entered, cleaned and analyzed using SPSS software version 16.0 for Windows. Different levels of significance were considered while comparing different parameters between individuals with and without MS. Since MS is a composite index created using five indicators like FBS, TAG, HDL-C, WC and blood pressure, these variables were not considered as independent variables in the logistic regression model.

\section{RESULTS}

There were 205 participants with mean age $48.40 \pm 12.96$ years in metabolic screening program. Among them $34.6 \%$ were male and $65.4 \%$ were female. The prevalence of MS as per the Joint Interim Statement 2009, IDF 2005 and NCEP ATP III 2001 criteria was $61.7 \%, 52.7 \%$ and $43.4 \%$ respectively (Figure 1).

There was significantly high TC, TAG, FBS, SBP and DBP and significantly low $\mathrm{HDL}$ in the individuals with $\mathrm{MS}$ compared to the normal individuals. The individuals with MS have significantly higher age and there was no significant difference in prevalence of MS between male and female (Table 1).

The chi-square test based on likelihood ratio is found to be 213.83 with a change (decrease) of 59.49 from the constant only model and is significant. This indicates that logistic regression model is fit statistically. Further, it revealed that included independent variables explained $34.2 \%$ of the variation in the dependent variable. The model suggests that age, BMI and family history of 
diabetes are the main predictors for being metabolic syndrome in our study population. The logistic regression revealed that one unit (year) increase in age will increase the chance of MS by $4.1 \%$ whereas one unit increase in BMI increases the risk by $27.6 \%$. Most importantly, the risk of MS for subject with family history of diabetes was 2.6 times higher than without the history (Table 2).

Figure 1. Prevalence of MS by using three different criteria

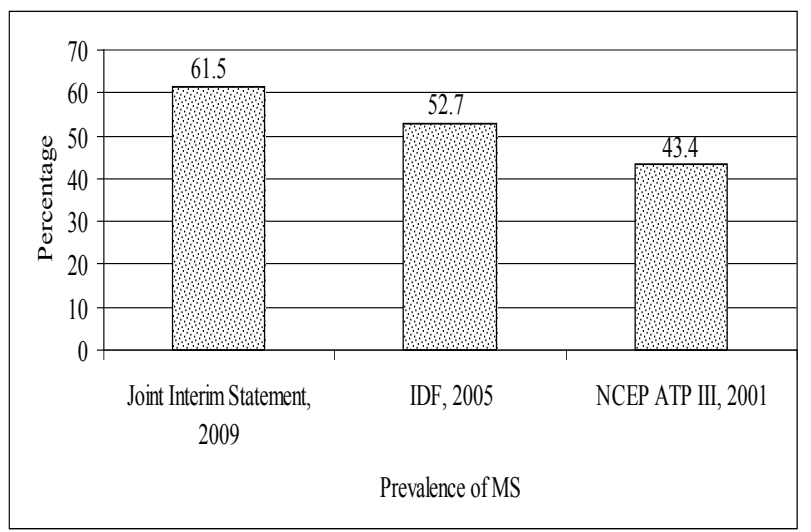

Table 1. Comparison of different parameters between individual with or without MS

\begin{tabular}{|c|c|c|c|c|c|c|}
\hline \multirow[t]{2}{*}{ Characteristics } & \multicolumn{6}{|c|}{ Metabolic Syndrome } \\
\hline & \multicolumn{3}{|l|}{ Yes } & \multicolumn{3}{|l|}{ No } \\
\hline Gender \% (M/F) & \multicolumn{3}{|l|}{$68 / 58$} & \multicolumn{3}{|l|}{$32 / 42^{\mathrm{NS}}$} \\
\hline \multicolumn{7}{|c|}{ Parametric: Independent Sample T Test } \\
\hline Characteristics & Number & Mean & SD & Number & Mean & SD \\
\hline Age of Patient & 126 & 51 & 12 & 79 & $45^{\mathrm{a}}$ & 14 \\
\hline $\begin{array}{|ll|}\text { Systolic } & \text { Blood } \\
\text { Pressure } & \\
\end{array}$ & 126 & 139 & 19 & 79 & $122^{\mathrm{a}}$ & 17 \\
\hline $\begin{array}{|ll|}\text { Diastolic } & \text { Blood } \\
\text { Pressure } & \\
\end{array}$ & 126 & 92 & 10 & 79 & $81^{a}$ & 10 \\
\hline FBS & 126 & 127 & 51 & 79 & $90^{\mathrm{a}}$ & 8 \\
\hline TC & 126 & 187 & 38 & 79 & $171^{\mathrm{b}}$ & 39 \\
\hline TAG & 126 & 172 & 123 & 79 & $89^{\mathrm{a}}$ & 55 \\
\hline LDL & 120 & 115 & 31 & 78 & $112^{\mathrm{NS}}$ & 33 \\
\hline $\mathrm{HDL}$ & 126 & 39 & 8 & 79 & $42^{c}$ & 9 \\
\hline \multicolumn{7}{|c|}{\begin{tabular}{|l|} 
Non-Parametric: Mann-Whitney Test \\
\end{tabular}} \\
\hline & Number & Median & IQR & Number & Median & IQR \\
\hline BMI & 120 & 26.1 & 4.5 & 78 & $23.1^{\mathrm{a}}$ & 5.8 \\
\hline WC & 120 & 89 & 11 & 78 & $78^{\mathrm{a}}$ & 13 \\
\hline
\end{tabular}

NS = not Significanta $=p$-value $\leq 0.001, b=p$-value $\leq 0.01$, $c=p$-value $\leq 0.05$
Table 2.Logistic Regression for the factors associated with metabolic syndrome

\begin{tabular}{|l|l|l|l|l|l|l|}
\hline Characteristics & B & S.E. & Wald & Df & Sig. & Exp(B) \\
\hline Age & 0.04 & 0.014 & 7.992 & 1 & 0.005 & 1.041 \\
\hline Gender & 0.222 & 0.426 & 0.271 & 1 & 0.603 & 1.248 \\
\hline Cholesterol & 0.004 & 0.004 & 0.732 & 1 & 0.392 & 1.004 \\
\hline BMI & 0.243 & 0.051 & 22.763 & 1 & 0.000 & 1.276 \\
\hline Alcohol & -0.278 & 0.386 & 0.517 & 1 & 0.472 & 0.757 \\
\hline $\begin{array}{l}\text { Family history } \\
\text { of diabetes }\end{array}$ & 0.955 & 0.418 & 5.221 & 1 & 0.022 & 2.600 \\
\hline $\begin{array}{l}\text { Family history } \\
\text { of hypertension }\end{array}$ & -0.617 & 0.391 & 2.496 & 1 & 0.114 & 0.539 \\
\hline Smoking & 0.713 & 0.595 & 1.434 & 1 & 0.231 & 2.040 \\
\hline Constant & -8.232 & 1.64 & 25.21 & 1 & 0.000 & 0.000 \\
\hline
\end{tabular}

\section{DISCUSSION}

In our study, we found a higher prevalence of MS according to IDF criteria compared to NCEP ATP III criteria which was similar to the results shown by the study done in Eastern Nepal $^{6}$, South India ${ }^{21}$, South Australia ${ }^{22}$ and United States ${ }^{23}$. There is significant difference in the prevalence of MS in different criteria for defining MS. Joint Interim Statement 2009 criteria shows higher prevalence of MS compared to IDF and NCEP ATP III criteria in the study population. The higher prevalence also indicates the higher sensitivity of Joint Interim Statement 2009 criteria in identifying $\mathrm{MS}$ in the individual. This in turn will be an indication of taking necessary preventive measures so that the risk of developing diabetes and cardiovascular disease can be lowered.

The prevalence of MS in this study population (52.7\%) is very high compared to the Eastern Nepal $(22.5 \%)^{6}$, South India $(25.8 \%)^{21}$, South Australia $(22.8 \%)^{22}$ and United States $(39 \%)^{23}$ according to IDF criteria. This higher prevalence, in this study, could be because of behavioral tendency of the study population to participate in the screening program when they have some problem. Therefore, it may not represent true prevalence of the population, however, this high prevalence does indicate MS is a public health problem in this population.

The logistic regression model used for the risk factor analysis showed independent significant association of age, BMI and family history of diabetes with MS which is similar to the study done by Chan et al in 
Chinese population. ${ }^{24}$ Ramachandran et al have shown the association of age, BMI and prior family history of diabetes with impaired glucose tolerance..$^{25}$ Therefore it is highly probable that increasing age, $\mathrm{BMI}$ and positive family history of diabetes in this study population predicts for impaired glucose tolerance which is a component of metabolic syndrome and hence leading to the risk of developing diabetes.

There is high prevalence of MS in the study population and therefore increasing the risk of developing diabetes and cardiovascular disease. Prevalence of MS could be similar in other urban areas of Nepal. Therefore, it is required to devise and implement the appropriate behavioral change and promotion program for life style modification along with the necessary medical intervention to prevent the progression of disease in the urban areas of the country.

\section{CONCLUSIONS}

There is high prevalence of MS in the study population. Age, BMI and family history of diabetes are found to be the main predictors for metabolic syndrome in our study population.

\section{REFERENCES}

1. Reaven GM. Banting lecture 1988: role of insulin resistance in human disease. Diabetes. 1988;37:1595-1607.

2. Zimmet PZ, Alverti G. The Metabolic Syndrome: Perhaps an etiologic mystery but far from a mythwhere does the International Diabetes Federation stand. Medscape Diabetes \& Endocrinology. 2005;7(2):261-78.

3. Isomaa B, Almgren P, Tuomi T et al. Cardiovascular morbidity and mortality associated with the metabolic syndrome. Diabetes Care.2001; 24:683-9.

4. Wasir JS, Misra A, Vikram NK, Pandey RM., Gupta R. Comparison of definitions of the metabolic syndrome in adult Asian Indians. J Assoc Physicians India. 2008;56:158-64.

5. Misra A, Vikram NK. Insulin resistance syndrome (metabolic syndrome) and obesity in Asian Indians: evidence and implications. Nutrition. 2004;20:482-91.

6. Prevalence of Hypertension, Obesity, Diabetes, and Metabolic Syndrome in Nepal Sanjib Kumar Sharma, AnupGhimire, Jeyasundar Radhakrishnan, Lekhjung Thapa, Nikesh Raj Shrestha, Navaraj Paudel, Keshar Gurung, Maskey
R, Anjali Budathoki, Nirmal Baral and David Brodie. International Journal of Hypertension. 2011:1-9

7. Pandey S, Baral N, Majhi S, Acharya P, Karki P, Shrestha S, Das BKL, Chandra L. Prevalence of the metabolic syndrome in acute myocardial infarction and its impact on hospital outcomes. Int J DiabDevCtries. 2009;29:52-5.

8. McKeigue PM, Pierpoint T, Ferrie JE, Marmot MG. Relationship of glucose intolerance and hyperinsulinaemia to body fat pattern in south Asians and Europeans. Diabetologia. 1992; 35:785-91.

9. McKeigue PM, Marmot MG, Syndercombe Court YD, Cottier DE, Rahman S, Riemersma RA. Diabetes, hyperinsulinaemia, and coronary risk factors in Bangladeshis in east London. Br Heart J. 1988;60:390-6.

10. King $H$, Aubert RE, Herman WH. Global burden of diabetes, 1995-2025: prevalence, numerical estimates, and projections. Diabetes Care. 1998;21:1414-31.

11. Reddy KS, Yusuf S. Emerging epidemic of cardiovascular disease in developing countries. Circulation. 1998;97:596-601.

12. Chobanian AV, Bakris GJ, Black HR, Cushman WC, Green LA, Izzo JL, Jones DW, Materson BJ, Oparil S, Jackson T. Wright JT, Roccella EJ and the National High Blood Pressure Education Program Coordinating Committee. The Seventh Report of the Joint National Committee on Prevention, Detection, Evaluation, and Treatment of High Blood Pressure. The JNC 7 Report. JAMA. 2003; 289:2560-72.

13. Raba J and Mottola HA. Glucose Oxidase as an Analytical Reagent. Critical Reviews in Analytical Chemistry. 1995;25(1):1-42.

14. Siedel J, Hagele EO, Ziegenhorn J and Wahlefeld AW. Reagent for the enzymatic determination of serum total cholesterol with improved lipolytic efficiency. Clin Chem. 1983;20:1075-81.

15. McGowan MW, Artiss JD and Zak BA. Peroxidase coupled method for the colorimetric determination of serum triglycerides. Clin Chem. 1983; 29:538-42.

16. Matthias Nauck, Winfried Ma" rz and Heinrich Wieland. New immunoseparation-based homogeneous assay for HDL-cholesterol compared 
with three homogeneous and two heterogeneous methods for HDL-cholesterol. Clin Chem. 1998;44 (7):1443-51.

17. Friedwald WT, Levy RI and Fredricson DS. Estimation of concentration of low-density lipoprotein in plasma, without use of preparative ultracentrifuge. Clin Chem. 1972;18:499-502.

18. Alberti KGMM, Eckel RH, Grundy SH, Zimmet $\mathrm{PZ}$, Cleeman JI, Donato KA, Fruchart JC, James WPT, Loria CM and Smith SC. Harmonizing the Metabolic Syndrome A Joint Interim Statement of the International Diabetes Federation Task Force on Epidemiology and Prevention; National Heart, Lung, and Blood Institute; American Heart Association; World Heart Federation; International Atherosclerosis Society; and International Association for the Study of Obesity. Circulation. 2009;120:1640-5.

19. National Cholesterol Education Program (NCEP) Expert Panel on Detection, Evaluation, and Treatment of High Blood Cholesterol in Adults (Adult Treatment Panel III). Third Report of the National Cholesterol Education Program (NCEP) Expert Panel on Detection, Evaluation, and Treatment of High Blood Cholesterol in Adults (Adult Treatment Panel III) final report. Circulation. 2002;106:3143-421.

20. Alberti KG, Zimmet P, Shaw J; IDF Epidemiology Task Force Consensus Group. The metabolic syndrome: a new worldwide definition. Lancet. 2005;366:1059-62.
21. M. Deepa1 S. Farooq1 M. Datta2 R. Deepa1, V. Mohan1* Prevalence of metabolic syndrome using WHO, ATPIII and IDF definitions in Asian Indians: The Chennai Urban Rural Epidemiology Study (CURES-34) Diabetes Metab Res Rev. 2007; 23:127-34.

22. Adams RJ, Appleton S, Wilson DH, et al. Population comparison of two clinical approaches to the metabolic syndrome. Implications of the new international diabetes federation consensus definition. Diabetes Care. 2005;28:2777-9.

23. Ko GT, Cockram CS, Chow C, et al. High prevalence of metabolic syndrome in Hong Kong Chinesecomparison of three diagnostic criteria. Diabetes Res ClinPract. 2005;69:160-8.

24. Chan JCN, Cheung JCK, Lau MC,jianWooa J, albert y.w. Chan AYW, Swaminathan R, Cockrama CS, Cark D.The Metabolic Syndrome in Hong Kong Chinese. Diabetes Care. 1996;19 (9):953-9.

25. Ramachandran A, Snehalatha C, Kapur A, Vijay V, Mohan V, Das AK, Rao P V, Yajnik CS, KumarKM. and NairJyotsna $D$, et al.High prevalence of diabetes and impaired glucose tolerance in India: National Urban Diabetes Survey. Diabetologia 2001;44 (9):1094-101. 